\title{
Microplasma Deposition of Biocompatible Coatings Using an Intelligent Robotic System for Plasma Processing
}

\author{
D.L. Alontseva ${ }^{a *}$, A.L. Krasavin ${ }^{a}$, M.B. ABilev ${ }^{b}$ And A.M. Zhilkashinova ${ }^{b}$ \\ ${ }^{a}$ D. Serikbayev East-Kazakhstan State Technical University, \\ 69 Protozanov St, Ust-Kamenogorsk, 070004, Kazakhstan \\ ${ }^{b} \mathrm{~S}$. Amanzholov East Kazakhstan State University, \\ 18/1 Amurskaya str., Ust-Kamenogorsk, 070002, Kazakhstan.
}

\begin{abstract}
This paper presents the method of microplasma deposition of biocompatible coatings using an intelligent robotic system for plasma processing. The two-layer coatings from biocompatible materials, namely from titanium wire and hydroxyapatite powders are sprayed on the surface of titanium substrates. The synthesis of hydroxyapatite powder suitable for applying biocompatible coatings onto medical implants is provided by chemical precipitation. Optimization of the synthesis parameters is carried out by the mathematical modelling method. The porosity of coatings is controlled by changing the spraying regime. The use of the intelligent robotic system for plasma processing allows movement of a robot arm along a given 3D-trajectory and accurate maintenance of plasma spraying parameters: the trajectory and travel speed of the plasma source, an angle between the sprayed surface and the plasma jet, and the distance from the plasma source to the surface of substrates. The composition and regimes of microplasma spraying of biocompatible coatings using an intelligent robotic system for plasma processing have been developed.
\end{abstract}

DOI: 10.12693/APhysPolA.136.310

PACS/topics: 81.15.-z, 81.07.-b, 68.47.Gh

\section{Introduction}

Nowadays a variety of porous metallic and ceramic materials are used to support biological fixation of implants [1-4]. Among them, plasma spray combined titanium/hydroxyapatite coatings are still very popular for manufacturing of orthopaedics implants mainly because of unique properties of titanium, including low weight, high specific strength, and good corrosion resistance [4], as well as high biocompatibility of hydroxyapatite [5]. Hydroxyapatite (HA) is the calcium phosphate mineral of the apatite group. In medical implantology, synthetic hydroxyapatite is used as implants coating, promoting a new bone formation [5-8]. Therefore research and development of new methods for the synthesis of fine crystalline HA, inexpensive and technological methods for formation of bioactive coatings is an urgent task. One of the main commercially viable methods of combined titanium/HA coatings manufacturing is plasma spraying $[2,4,8]$. The porous structure of the coating, developed by the plasma spraying method, promotes effective intergrowth of the bone tissue into the implant pores significantly, which in turn, contributes to its reliable fixation in the bone. The plasma coating of surfaces of complex configurations, such as the medical implants of endoprostheses, presents a challenge for the implementation of the plasma spraying technology. This requires automated manipulations of the plasma jet

*corresponding author; e-mail: dalontseva@mail.ru and/or the substrate along with the robotic control for appropriate treatment of a surface $[9,10]$. Deviation from the desirable spraying angle to the surface and required spraying distance, as well as a predetermined constant speed of the plasma source movement along the surface can compromise coating properties.

The aim of this paper was to develop a robotic microplasma spraying technology for biocompatible coatings with a focus on the synthesis of HA powders, choice of spray modes to ensure the desired porosity of coatings and development of algorithms for controlling a robot manipulator.

\section{Materials and methods}

Grade 5 ELI titanium alloy samples were used as substrates for microplasma spraying. The reference standard composition of such grade in wt\% of $\mathrm{Ti}$ basis is as follows: $\mathrm{Fe}-0.25-0.40, \mathrm{~N}-0.05 \%, \mathrm{O}-0.13-0.20$, $\mathrm{Al}-5.50-6.75, \quad \mathrm{C}-0.08, \quad \mathrm{~V}-3.50-4.50, \quad$ and $\mathrm{H}-0.015$.

For the application of titanium coating, a wire of $0.3 \mathrm{~mm}$ in diameter was used from titanium of BT-1-00 (GOST 19807-91) Grade 4. The composition of such grade in wt\% (Max) of Ti-base is as follows: $\mathrm{N}-0.05$, $\mathrm{C}-0.1, \mathrm{Fe}-0.5, \mathrm{H}-0.0015, \mathrm{O}-0.5$. As the top layer coating material, HA powder with the fraction sizes of $40-90 \mu \mathrm{m}$ and with a large size difference across the particle axes was used. The phase composition of the HA powder was an all-crystalline combination of $\mathrm{Ca}_{10}\left(\mathrm{PO}_{4}\right)_{6}(\mathrm{OH})_{2}$ with a molar ratio $\mathrm{Ca} / \mathrm{P}-1.67$. The HA powder was synthesized by chemical precipitation [11]. 
Before microplasma spraying a gas-abrasive treatment of substrates was carried out using the electrocorundum of 25A Grade (GOST 2MT 793-80) followed by ultrasonic cleaning in medical alcohol for $15 \mathrm{~min}$.

The research was carried out at a pilot production site established in D. Serikbayev East Kazakhstan State Technical University with an industrial complex for plasma processing of materials on the basis of Kawasaki RS-010LA (Kawasaki Robotics, Japan), an industrial robot. The robot consists of movable parts with six degrees of mobility for moving the equipment installed therein according to a predetermined trajectory. The robot arm is equipped with the MPN-004 microplasmatron produced by E.O. Paton Institute of Electric Welding (Ukraine) for microplasma deposition of wire or powder coatings (Fig. 1a). The Kawasaki RS-010LA robot manipulator characteristics are as follows: positioning accuracy - $0.06 \mathrm{~mm}$; maximal linear speed $13100 \mathrm{~mm} / \mathrm{s}$; engagement zone - $1925 \mathrm{~mm}$; working load capacity - $10 \mathrm{~kg}$. Kawasaki robots are controlled by AS software system.
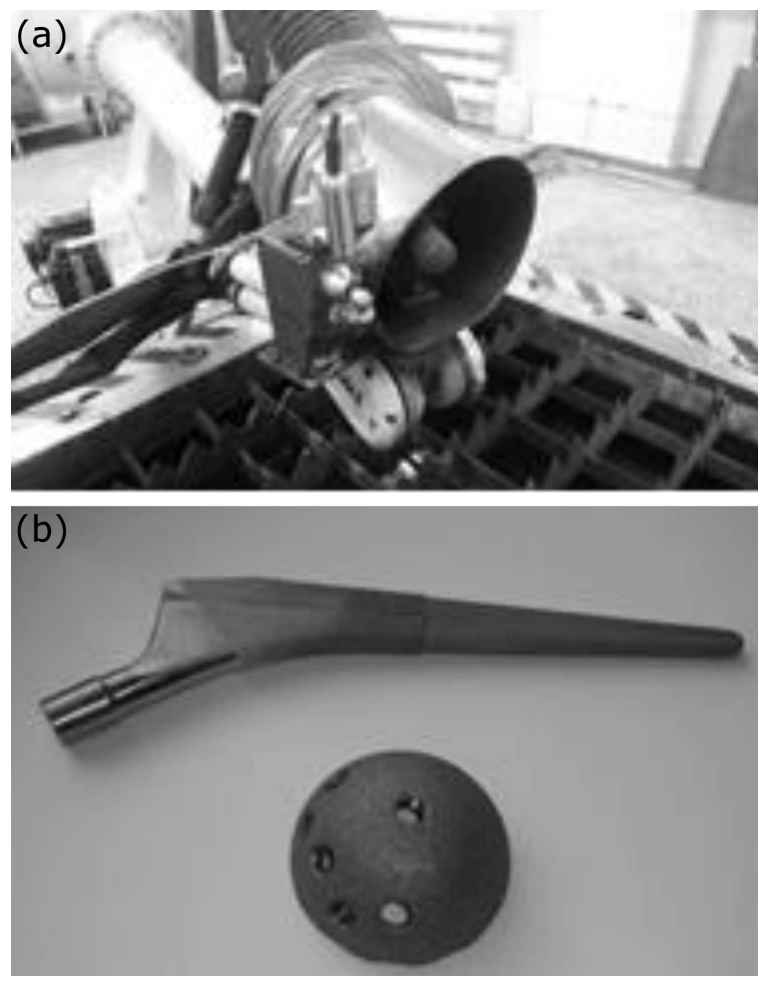

Fig. 1. General view of Kawasaki RS-010LA robot manipulator with MPN-004 microplasmatron (a) and a set of hip joint endoprosthesis with a two-layer microplasma sprayed coating (b).

The methods of control theory, linear algebra, and mathematical modelling were applied to develop control algorithms for the robot manipulator.

The experimental methods of analysis include Scanning Electron Microscopy (SEM) by JSM-6390LV ("JEOL", Japan), X-ray diffraction (XRD) by X'Pert PRO ("PANalytical", the Netherlands), and Infrared
Spectroscopy by FT-801 spectrometer (SIMEX, Russia). The SEM-images of cross sections of coatings were processed using ZAF/PB, Micro Capture, and Atlas software for evaluating coating porosity. No clinical tests on humans or animals have been carried out.

\section{Results and discussion}

Optimization of HA synthesis parameters was performed for the hydroxyapatite samples with a given $\mathrm{Ca} / \mathrm{P}$ ratio by the mathematical modelling method based on the generalized Protodyakonov equation [12] As variable factors, the following six were chosen: time of precipitate synthesis, the precipitate aging time, $\mathrm{pH}$, temperature, concentration of calcium nitrate, and concentration of ammonium hydrophosphate. The optimal parameters of HA powders synthesis were determined as follows: the time of synthesis - $60 \mathrm{~min}$; the aging time of the precipitate $-16 \mathrm{~h}$; the $\mathrm{pH}-9$; the temperature $-50^{\circ} \mathrm{C}$, the concentration of calcium nitrate $-1 \mathrm{~mole} / \mathrm{l}$; the concentration of ammonium hydrophosphate - 0.6 mole $/ 1$. To get the desirable HA particle size and crystallinity the synthesized $\mathrm{HA}$ was subjected to heat $\left(800^{\circ} \mathrm{C}\right)$ and ultrasonic ( $60 \%$ of the power generator) treatments. At these conditions, the synthesized HA has the maximum crystallinity $95.67 \%$ and minimum average particle size of 40-90 $\mu \mathrm{m}$. The derived mathematical models of process optimization made it possible to calculate the conditions for the synthesis by changing at least one of the variable factors in the studied ranges in order to obtain HA with a given stoichiometric composition 1.67, particle size, and solubility.

It was shown by the previous researchers $[2,13,14]$ that the biocompatible coatings should have macro- (the pore size not smaller than $100 \mu \mathrm{m}$ ) and micro-porosity (the pore size not larger than $20 \mu \mathrm{m}$ ) because the multiscale porous coating can perform better than that with only one dimensional porosity and an overall porosity range should be no less than 25 vol.\%. A layer of hydroxyapatite should be applied over the porous titanium coating. The ingrowth of bone into the titanium sublayer will ensure the essential strength of the implant's integration to the bone, and the hydroxyapatite coating will provide necessary biocompatibility. When selecting the thickness of applied layers, it was taken into account that in the case of microplasma application of biocompatible coatings with a thickness of smaller than $200 \mu \mathrm{m}$, a large pore size of about $150 \mu \mathrm{m}$ can result in formation of porosity throughout its thickness. This can cause an adverse contact and interaction of the implant metal with the internal environment. In addition, a titanium sublayer with the well-designed surface morphology improves the adhesion strength of the hydroxyapatite layer to the implant surface.

The statistically designed experiments based on a factorial technique described in paper [15] were used to establish correlations between coatings porosity and microplasma spraying parameters. As variable parameters, 
the following were chosen: current, carrier plasma gas consumption, traverse velocity, spray distance, and wire or powder feed. Studies of the effects of these parameters on porosity and coating thickness were carried out. Plasma spraying was made using nine different regimes and the coatings porosity was analysed. The optimum combination of input variables for achieving the required qualities of coatings was selected.

The microplasma deposition of two-layer titanium/hydroxyapatite coating to the surface of implants was carried out (Fig. 1b). The parameters for applying two-layer coatings from Ti-wire and HA-powders with an average particle diameter of $50-80 \mu \mathrm{m}$ to titanium alloy substrates are presented in Table I. These regimes provide the desired coating thickness (up to $300 \mu \mathrm{m}$ ) and the average pore size from $20 \mu \mathrm{m}$ to $150 \mu \mathrm{m}$ with a pore volume ratio of about $30 \%$. The images of the structure of titanium coatings obtained by microplasma deposition with the indicated modes are shown in Fig. 2a, b.
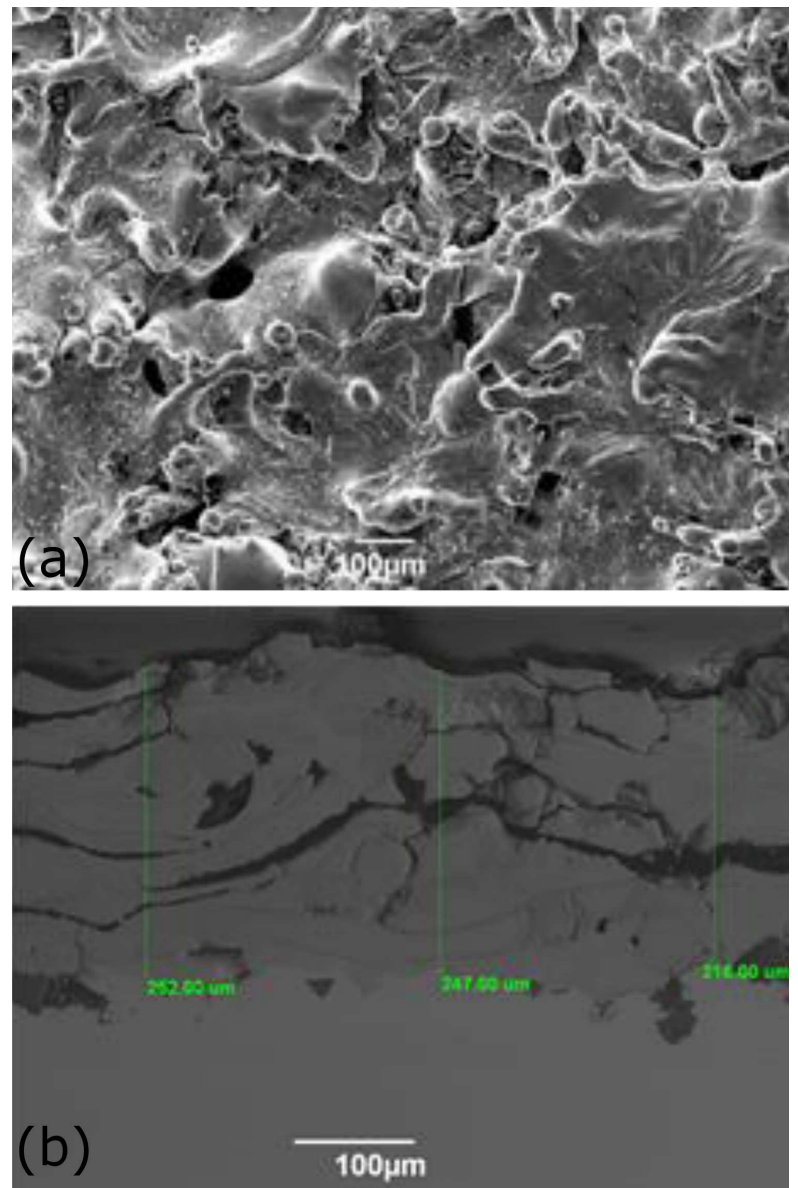

Fig. 2. SEM-images of porous microplasma nitanium coating: the surface (a), the cross section (b).

To provide the microplasma deposition with the parameters specified in Table I, an innovative control algorithm for the robot manipulator described by a linear second order ordinary differential equation as well as
Microplasma spraying parameters

TABLE I

\begin{tabular}{|c|c|c|}
\hline \multirow[t]{2}{*}{ Spray parameters } & \multicolumn{2}{|c|}{$\begin{array}{l}\text { The coating materials } \\
\text { and setting parameters }\end{array}$} \\
\hline & Ti-wire & HA-powders \\
\hline primary gas & \multicolumn{2}{|r|}{ argon } \\
\hline powder carrier gas & \multicolumn{2}{|r|}{ argon } \\
\hline traverse velocity $[\mathrm{mm} / \mathrm{s}]$ & \multicolumn{2}{|r|}{50} \\
\hline substrate pre-heat temperature $\left[{ }^{\circ} \mathrm{C}\right]$ & \multicolumn{2}{|r|}{-} \\
\hline post-spray heat temperature $\left[{ }^{\circ} \mathrm{C}\right]$ & \multicolumn{2}{|r|}{-} \\
\hline current $[\mathrm{A}]$ & 16 & 45 \\
\hline carrier gas flow rate $[\mathrm{l} / \mathrm{h}]$ & 140 & 60 \\
\hline spray distance [mm] & 40 & 160 \\
\hline feed rate of wire $[\mathrm{m} / \mathrm{min}]$ & & \\
\hline or powder $[\mathrm{g} / \mathrm{min}]$ & 3 & 0.4 \\
\hline
\end{tabular}

a tracking system for 3D scanning of the part processing area based on an algorithm for compensating object dynamics and perturbations were developed. The description of these automation solutions requires separate consideration in a specialized journal. Here it is noted that the use of these algorithms allows us to control the spray distance and traverse velocity presented in Table I as well as the required trajectory of microplasmatron (the plasma jet is directed perpendicularly to the substrate surface).

\section{Conclusion}

The synthesis of HA powders by chemical precipitation is conducted. The synthesis parameters were optimized by means of the mathematical modeling method. The composition and regimes of microplasma deposition of two-layer coatings for titanium implants, including a sub-layer of a porous titanium coating with a thickness of $200-300 \mu \mathrm{m}$ with a pore size of $20-150 \mu \mathrm{m}$ and a pore volume ratio of about $30 \%$ controlled by changing the spraying regime, and an upper layer of hydroxyapatite with a thickness of up to $200 \mu \mathrm{m}$ was deposited. The intelligent robotic system for plasma processing was used to allow movement of a microplasmatron along a given 3D trajectory and accurate maintainance of plasma spraying parameters: the trajectory and travel speed of the plasma source, an angle between the sprayed surface and the plasma jet, as well as the distance from the plasma source to the substrates surface. The research results are of significance for a wide range of researchers developing the technologies of plasma deposition of biocompatible coatings.

\section{Acknowledgments}

The authors thankfully acknowledge the funding provided by the Scientific Committee of the Ministry of Education and Science of the Republic of Kazakhstan for the project AP05130525 "The intelligent robotic system for plasma processing and cutting of large-size products of complex shape". 


\section{References}

[1] S.B. Goodman, Z. Yao, M. Keeney, F. Yang, Biomaterials 34, 3174 (2013).

[2] F. Matassi, A. Botti, L. Sirleo, C. Carulli, M. Innocenti, Clin. Cases Miner. Bone Metab. 10, 111 (2013).

[3] D.W. Fabi, B.R. Levine, in: ASM Handbook: Materials for Medical Devices, Vol. 23, Ed. R. Narayan, ASM International, USA 2012, p. 307.

[4] R.B. Heimann, Surf. Coat. Tech 201, 2012 (2006).

[5] J.M. Oliveira, S.S. Silva, P.B. Malafaya, M.T. Rodrigues, N. Kotobuki, M. Hirose, M.E. Gomes, J.F. Mano, H. Ohgushi, R.L. Reis, J. Biomed. Mater. Res. A. 91A, 175 (2009).

[6] Y. Jinfeng, C. Haodong, G. Qi, L. Zhigang, Bio-Med. Mater. Eng. 29, 229 (2018).

[7] S. Sakka, J. Bouaziz, F.B. Ayed, in Advances in Biomaterials Science and Biomedical Applications, Ed. R. Pignatello, InTech, London 2013, p. 23.

[8] A.V. Lyasnikova, O.A. Markelova, V.N. Lyasnikov, O.A. Dudareva, Mech. Compos. Mater. 51(6), 801 (2016).

[9] A. Vardelle, C. Moreau, J. Nickolas, A. Themelis, Plasma Chem. Plasma Process. 35, 491 (2015).
[10] D.L. Alontseva, S.G. Voinarovych, O.N. Kyslytsia, A.V. Dzhes, A.V. Russakova, N.V. Prokhorenkova, A.L. Krasavin, M.O. Leonova, Basic Problems of $\mathrm{Ma}$ terial Science 15, 135 (2018).

[11] M.B. Abilev, A.V. Troyeglazova, K. Akatan, D.L. Alontseva, in: Sviridov Readings, Proc. 8th Int. Conf. of Chemistry and Chemical Education, 2018, Eds. T.N. Vorobyova, E.I. Vasilevskaya, KrasikoPrint, Minsk 2018, p. 25.

[12] B. Dabrowski, W. Swieszkowski, D. Godlinski, K.J. Kurzydlowski, J. Biomed. Mater. Res. B Appl. Biomater. 95, 53 (2010).

[13] J.R. Woodard, A.J. Hilldore, S.K. Lan, C.J. Park, A.W. Morgan, J.A. Eurell, S.G. Clark, M.B. Wheeler, R.D. Jamison, A.J. Wagoner Johnson, Biomaterials. 28, 45 (2007).

[14] Lesson 12: Advanced Topics I - Generalized Estimating Equations (GEE), in STAT 504 - Analysis of Discrete, The Pennsylvania State University online courses, 2018.

[15] D. Thirumalaikumarasamya, K. Shanmugama, V. Balasubramanian, Prog. in Nat. Sci.: Mater. Int. 22, 468 (2012). 